\title{
Avaliação do deslocamento de minhocas (Eudrilus eugeniae) submetidas a pulsos elétricos controlados
}

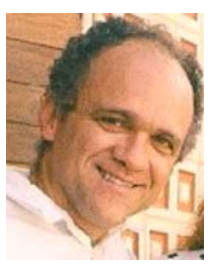

\author{
Delly Oliveira Filho1', Isnard D. Ferraz², José H. Martins', Luiz C. dos Santos', \\ Osvaldo P. Ribeiro Filho ${ }^{3} \&$ Douglas R. da Costa ${ }^{4}$
}

${ }^{1}$ DEA/UFV. Viçosa, MG, CEP 36570-000, Fone: (31) 3899-1897, E-mail: delly@ufv.br,

${ }^{2}$ Central de Desenvolvimento Agrário de Florestal, UFV, Fone: (31) 3536-2266,E-mail: iferraz@ufv.br, jmartins@ufv.br,

${ }^{3}$ Dep. de Biologia Animal, UFV, Fone: (31) 3899 1305, E-mail: Icsantos@ufv.br, oribeiro@ufv.br

${ }^{4}$ Mestrando em Eng. Agrícola, UFV, Fone: (31) 3899-1930, E-mail: douglascosta@vicosa.ufv.br

Protocolo $161-2 / 4 / 2004$ - Aprovado em 30/3/2005

\begin{abstract}
Resumo: Realizou-se este trabalho com o objetivo de determinar, em laboratório, os índices de deslocamento e de separação de minhocas gigante africana (Eudrilus eugeniae) do húmus, e definir as características elétricas dos pulsos elétricos que permitam melhor eficiência na separação de minhocas em escala piloto. Os testes realizados apresentavam as seguintes características: (i) tensão de 100 a 500 V; (ii) patamar de pulso de 2, 3 e 4 ms; (iii) freqüência de 1 e $5 \mathrm{~Hz}$; e (iv) tempo de exposição de 1, 2, 3 e $4 \mathrm{~h}$. Verificou-se que as minhocas submetidas aos pulsos elétricos se deslocam, preferencialmente, no sentido do cátodo. Nas situações estudadas o maior valor de índice de deslocamento obtido foi de $78,18 \%$ e o índice de separação, de $62,37 \%$. A utilização de pulsos elétricos controlados, para a separação de minhocas do húmus, gera um ganho médio, ao longo da vida útil estimada, de cerca de $26 \%$ de economia financeira.
\end{abstract}

Palavras-chave: características elétricas, separação de minhocas, pulsos elétricos na minhocultura

\section{Evaluation of the displacement of earthworms (Eudrilus eugeniae) submitted to controlled electric pulses}

\begin{abstract}
The objective of this work was to determine, in laboratory, the displacement index and the separation index of earthworms (Eudrilus eugeniae) from the humus, to define the characteristics of the electric pulses that allow better efficiency in the separation of earthworms in pilot scale. The tests presented the following characteristics: (i) tension - 100 to $500 \mathrm{~V}$; (ii) pulse level - 2.3 and $4 \mathrm{~ms}$; (iii) frequency - 1 and $5 \mathrm{~Hz}$; (iv) exhibition time - 1, 2, 3 and $4 \mathrm{~h}$. It was verified that the earthworms submitted to the electric pulses preferentially move towards the cathode. For the studied situations the highest value obtained for the displacement index was $78.18 \%$, while the separation index was $63.37 \%$. The utilization of controlled electric pulses for the earthworm separation from the substrate generate mean gain along the estimated useful life of, around $26 \%$ of economic savings.
\end{abstract}

Key words: electric characteristics, earthworm separation, electric pulses

\section{INTRODUÇÃO}

O papel desempenhado pelas minhocas nos solos, seja por suas galerias ou pelos excrementos, reveste-se de suma importância, de vez que sua intervenção é importante e decisiva para a formação do húmus natural, componente imprescindível às terras férteis. Elas modificam profundamente as características físicas do solo, misturando seus horizontes e aumentando a aeração, a drenagem e o poder de retenção de água e de substâncias úteis. Em suas dejeções, concentramse nutrientes necessários ao crescimento dos vegetais, como nitrogênio, fósforo, potássio e cálcio, dentre outros (Motter et al., 1990).

A criação de minhocas tem despertado o interesse de muitos produtores, em função do baixo investimento inicial, necessidade de pouco espaço físico e da possibilidade de proporcionar atraentes taxas de retorno. $O$ húmus pode ser utilizado na própria propriedade ou, ainda, no paisagismo e jardinagem, floricultura, fruticultura e outros (Martinez, 1995). Os resíduos orgânicos gerados pelos sistemas produtivos, agropecuários, industriais e até pelas atividades domésticas, podem ser transformados pelo processo de vermicompostagem, em fonte de nutrientes, 
tanto para a produção agrícola quanto para a produção de minhocas, que podem ser utilizadas na alimentação animal (Vieira, 1997).

Segundo Calvert (1979), o processo utilizado na coleta de minhocas, quando produzidas em larga escala, pode ser um fator limitante desta atividade. Na minhocultura comercial, o processo de separação é a etapa mais trabalhosa e deve ser feita com muito cuidado, em razão da fragilidade dos vermes, evitando injúrias e, mesmo, a redução drástica de sua população.

Os métodos mais usados são a separação manual, a migratória e a mecânica. A separação manual e a migratória são mais indicadas quando se pretende comercializar as minhocas como matrizes ou iscas, porém a separação manual é um processo que requer mão-de-obra intensiva, influenciando a atratividade econômica da minhocultura; e a migratória, apesar de resultar em menor índice de lesões, estresse e morte, requer um tempo maior na separação das minhocas, podendo chegar a dias e, ainda assim, não se obter pleno sucesso na separação, o que torna necessária a implementação de métodos complementares (Righi, 1989). A separação mecânica, apropriada para grandes produtores, não é indicada para coleta de matrizes ou de iscas vivas para pesca, pois as minhocas podem sofrer ferimentos ou até morrer, mas é recomendada, no entanto, para colheita destinada à alimentação animal e/ou produção de húmus, pois possibilita processar grande quantidade de substrato em menor tempo (SENAR, 1994).

Em locais inadequados à aplicação de produtos químicos, tem-se usado estímulos elétricos para fazer com que as minhocas subam à superfície. O método elétrico é menos nocivo quando comparado com o químico (permanganato de potássio e formalina) e se mostrou eficaz na retirada das minhocas do solo (Satchell, 1955). A utilização de pulsos elétricos controlados minimiza o tempo gasto na coleta, otimizando o uso da mão-deobra, além de evitar danos físicos às minhocas; podem ser utilizados tanto na produção de húmus como de matrizes e iscas (Moraes, 1999).

Dentre as espécies de minhocas utilizadas comercialmente, a vermelha-da-califórnia (Eisenia fotida) e a gigante-africana (Eudrilus eugeniae) se destacam, despertando maior interesse entre os criadores. A primeira espécie, devido à sua capacidade de decompor rapidamente materiais biodegradáveis; a segunda, por se tratar de minhocas vorazes, capazes de consumir grandes quantidades de alimentos, equivalentes ao seu peso, por dia (Reinecke \& Kriel, 1981).

A gigante-africana (Eudrilus eugeniae) é uma espécie da família eudrilidae, adaptada ao clima tropical, com temperatura ideal em torno de 20 a $25{ }^{\circ} \mathrm{C}$, não suportando valores abaixo de $15{ }^{\circ} \mathrm{C}$; apresenta comprimento médio de 20 a $22 \mathrm{~cm}$, podendo chegar a $37 \mathrm{~cm}$, e massa de 6,5 g, aos 130 dias de vida. São comercializadas como isca para pesca no tamanho de 13 a 15 cm (Almeida, 1999; Ávila, 1999; Martinez, 1995).

Bradway \& Moore (1940), estudando a ação da corrente elétrica em minhocas e utilizando pilha elétrica produzindo 2 volts de tensão e 0,1 miliampéres de corrente, verificaram que, quando a corrente elétrica flui transversalmente através do animal ou de um pedaço dele, os músculos respondem por uma contração unilateral para o cátodo. $O$ resultado é que a minhoca se curva em forma de $U$, apontando a cabeça e a cauda para o cátodo, mantendo a parte central mais próxima do ânodo. Os impulsos para o galvanotropismo são produzidos pelo cordão nervoso, enquanto a ação primária da corrente se dá nos elementos desse cordão. Constataram, ainda, que se a corrente flui através da minhoca com o cátodo na cabeça do animal (galvanotropismo catódico), ocorre a contração da musculatura circular e a minhoca se alonga ao máximo de seu comprimento. Quando a corrente é invertida, tal que o ânodo esteja na cabeça (galvanotropismo anódico), os músculos longitudinais se contraem, fazendo com que a minhoca diminua o seu comprimento durante o fluxo de corrente.

Em estudos de propriedades bioelétricas em minhocas Eisenia foetida, Kurtz \& Schrank (1955) determinaram a distribuição longitudinal do potencial elétrico ao longo do lado dorsal de minhocas adultas cliteladas, cujas medidas mostraram que a cabeça é mais eletronegativa que a cauda e a parte mais eletronegativa é a região do clitelo. A diferença de potencial média, medida entre os extremos da minhoca, foi de $14 \mathrm{mV}$ e da região do clitelo de $16 \mathrm{mV}$.

A separação de minhocas do solo é um dos maiores problemas técnicos em estudos de populações e na minhocultura. O método de captura em que se emprega eletricidade, sofre limitações básicas devido à não homogeneidade do solo, pois diferenças nas suas estruturas ou a distribuição de umidade, pode influenciar a ação do campo elétrico; logo, o teor de umidade do solo é um dos fatores de maior importância na eficiência da separação, devido à sua influência na resistividade do solo (Rusthon \& Luff, 1984; Thielemann, 1986).

Quando submetidas ao efeito da corrente elétrica, as minhocas reagem à quantidade de carga por unidade de tempo e área que percorre seus corpos e provoca, nas células, uma distribuição das cargas ou até mesmo uma dissociação eletrônica (Thielemann, 1986):

$$
\sigma=\frac{\mathrm{Q}}{\mathrm{tS}}
$$

em que:

$$
\begin{aligned}
& \sigma \text { - densidade de corrente, } \mathrm{A} \mathrm{m}^{-2} \\
& \mathrm{Q} \text { - quantidade de carga, } \mathrm{C} \\
& \mathrm{t} \text { - tempo, } \mathrm{s} \\
& \mathrm{S} \text { - área, } \mathrm{m}^{2}
\end{aligned}
$$

$\mathrm{Na}$ Eq. 1 está implícita a intensidade da corrente elétrica que, pela lei de Ohm, é proporcional à tensão e depende da resistência elétrica, significando que a intensidade da tensão para uma resistência do solo, provoca a respectiva ação na minhoca, razão por que Thielemann (1986) afirma que é preciso considerar, numa minhoca apenas, a diferença de potencial entre a começo e o fim do seu corpo; portanto, um mesmo sinal elétrico é sentido com menor efeito por um animal pequeno que por um animal grande.

Thielemann (1986) salientou que em um método elétrico efetivo de captura, precisa-se levar em conta os seguintes pontos: i) a produção de um campo elétrico homogêneo, de modo a predominar, em toda a área pesquisada, as mesmas 
condições, e ii) a definição de uma área de concentração. Afirmou, ainda, que a área de influência do método elétrico descrito por Rushton \& Luft (1984) não possui um campo elétrico homogêneo, de vez que a densidade linear do campo elétrico, uma medida relativa para a intensidade do campo por unidade de área, se altera proporcionalmente com o valor da distância para o eletrodo central. Dentro do campo elétrico as minhocas estão expostas, portanto, em função da posição, a diferentes tensões.

Moraes (1999), utilizando uma estrutura que permitia deslocamento máximo de $50 \mathrm{~cm}$ às minhocas submetidas aos testes, em uma camada de $3 \mathrm{~cm}$ de húmus, constatou o fenômeno da atração involuntária das minhocas submetidas aos pulsos elétricos. Avaliando o efeito do campo elétrico sobre o índice de deslocamento de minhocas produzido por sinais elétricos de corrente contínua (CC), corrente alternada (CA), onda pulsativa (OP) e pulsos controlados (PC) nas espécies Eudrilus eugeniae (gigante africana) e Eisenia foetida (vermelha da califórnia), constatou que a utilização de pulsos elétricos é viável tecnicamente para separação de minhocas do húmus. $\mathrm{O}$ melhor valor do índice de deslocamento utilizado para verificar a eficiência de separação, foi da ordem de $83,7 \%$ para a espécie Eudrilus eugeniae é de 93,5\% para a espécie Eisenia fotida. Esses valores foram obtidos quando se aplicaram pulsos controlados com as seguintes características: (i) tensão de 100 $\mathrm{V}$, patamar de pulso de $4 \mathrm{~ms}$, freqüência de $1 \mathrm{~Hz}$ e tempo de exposição de $20 \mathrm{~min}$, para a espécie Eudrilus eugeniae; e (ii) tensão de $200 \mathrm{~V}$, patamar de pulso de $3 \mathrm{~ms}$, freqüência de $1 \mathrm{~Hz}$ e tempo de exposição de $30 \mathrm{~min}$, para a espécie Eisenia foetida.

Ante o exposto objetivou-se, com este trabalho, definir sobretudo as características dos sinais elétricos que permitam melhor eficiência na separação de minhocas em canteiros comerciais.

Especificamente, o presente estudo visou:

1. determinar o índice de deslocamento $\left(\mathrm{I}_{\mathrm{D}}\right)$ e o índice de separação $\left(\mathrm{I}_{\mathrm{S}}\right)$ de minhocas Eudrilus eugeniae (Gigante Africana) e submetidas a pulsos elétricos controlados.

2. efetuar a análise da viabilidade econômica da separação de minhocas do húmus com a utilização de pulsos elétricos controlados.

\section{MATERIAL E MÉTODOS}

O presente trabalho foi desenvolvido no Laboratório da Área de Energia do Departamento de Engenharia Agrícola e no Setor de Piscicultura do Departamento de Biologia Animal, ambos da Universidade Federal de Viçosa. Utilizaram-se minhocas da espécie Eudrilus eugeniae, procedentes do minhocário do Setor de Piscicultura. O substrato utilizado foi esterco bovino, já vermicompostado, isento de minhocas e pré-secado, peneirado em malha de $2 \mathrm{~mm}$.

\section{Determinação dos índices de deslocamento $\left(I_{D}\right)$ e de separação $\left(I_{S}\right)$}

Dentro do recipiente de testes foram colocados os eletrodos na forma de tela de arame de aço com bitola de $3 \mathrm{~mm}$, distanciados 0,90 m entre si deixando-se, em cada lado da caixa, uma região de escape de $0,10 \mathrm{~m}$ de comprimento por $0,50 \mathrm{~m}$ de largura. Entre os eletrodos que se encontravam conectados ao aparelho, foi posto húmus até a altura de $0,30 \mathrm{~m}$.

Próximo ao ânodo foi delimitada uma região de $0,10 \times 0,50 \mathrm{x}$ $0,30 \mathrm{~m}$, denominada região de acomodação, onde foram colocadas 70 minhocas que ali permaneceram durante $30 \mathrm{~min}$. Transcorrido esse tempo, era retirado o delimitador da região de acomodação e o aparelho era ligado, expondo as minhocas aos pulsos (Figura 1).

Depois da exposição durante 1, 2, 3 e 4 h, desligava-se o gerador de pulsos e eram inseridas quatro placas de aço galvanizado de $0,40 \times 0,50 \mathrm{~m}$ na caixa de testes, dividindo-a em sete seções: quatro seções de $0,20 \times 0,50 \times 0,30 \mathrm{~m}$ e três seções de 0,10 x 0,50 x 0,30 m (Figura 2). Contava-se o número de minhocas por seção, incluindo as áreas de escape (seções 0 e 6).

A fim de se determinar os índices de separação e de deslocamento das minhocas quando submetidas a pulsos elétricos controlados, considerou-se o seguinte; para cada seção de comprimento $0,20 \mathrm{~m}$, foi atribuído um peso, sendo zero para a região de acomodação (seção 1) e crescente de uma unidade até a seção 4. Às regiões de escape foram atribuídos pesos máximos (4) e, à região anterior ao cátodo (seção 5) peso 3,5 , pois apresenta metade da largura das demais regiões.

Determinou-se o índice de deslocamento $\left(\mathrm{I}_{\mathrm{D}}\right)$ utilizando-se a Eq. 2:

$$
\mathrm{I}_{\mathrm{D}}=\frac{\sum_{\mathrm{S}=0}^{6} \mathrm{n}_{\mathrm{S}} \mathrm{p}_{\mathrm{S}}}{\mathrm{NP}} 100
$$

em que:

$\mathrm{n}_{\mathrm{S}}$ - número de minhocas da seção s depois da exposição aos pulsos

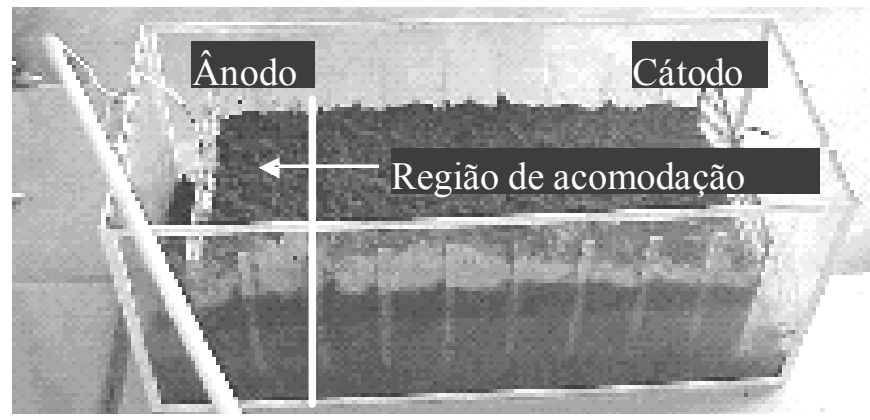

Figura 1. Estrutura de testes para aplicação do pulso

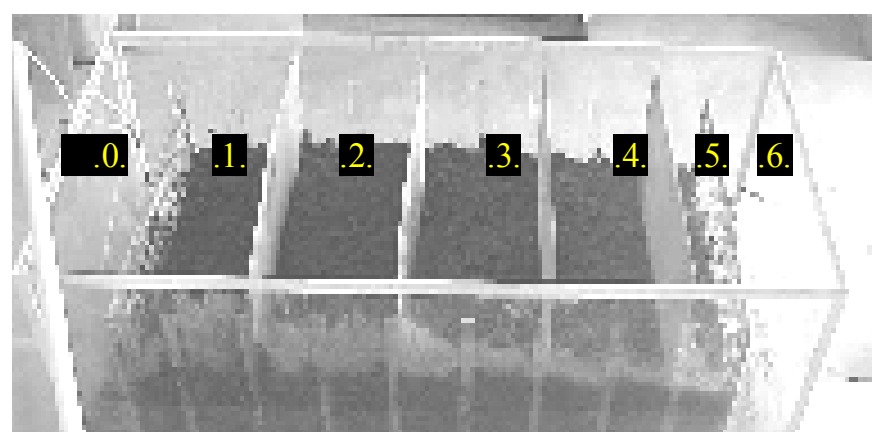

Figura 2. Estrutura de testes com a delimitação das seções 
$\mathrm{p}_{\mathrm{s}}$ - peso da seção $\mathrm{s}$

$\mathrm{N}$ - número total de minhocas

$\mathrm{P}$ - peso máximo atribuído

O índice de separação $\left(\mathrm{I}_{\mathrm{S}}\right)$ foi determinado pela Eq. 3:

$$
\mathrm{I}_{\mathrm{S}}=\left(\frac{\mathrm{n}_{0}+\mathrm{n}_{5}+\mathrm{n}_{6}}{\mathrm{~N}}\right) 100
$$

em que:

$\mathrm{n}_{0}$ - número de minhocas na seção 0 , região de escape anterior ao ânodo

$\mathrm{n}_{5}$ - número de minhocas na seção 5 , região imediatamente anterior ao cátodo

$\mathrm{n}_{6}$ - número de minhocas na seção 6, região de escape posterior ao cátodo

$\mathrm{N}$ - número total de minhocas utilizadas nos testes

A partir do posicionamento das minhocas ao longo da caixa de testes após a conclusão de cada repetição, fez-se uma simulação considerando-se a distribuição uniforme das minhocas ao longo da caixa e que apresentariam a mesma tendência de deslocamento observada nos testes determinando-se, em seguida, os índices médios de deslocamento e de separação.

\section{Controle de sobrevivência}

Ao final de cada teste, as minhocas foram contadas e colocadas em potes de plástico, com $2 / 3$ de seu volume previamente preenchido com esterco curtido, apresentando teor de umidade em torno de $70 \%$ base úmida. A cada sete dias procedia-se à contagem dos vermes em cada pote e se verificava o percentual de sobrevivência, o qual foi determinado fazendose a razão entre o número de minhocas contadas em cada observação e o número total de minhocas colocadas nos potes, ao final de cada repetição.

\section{Testes em escala-piloto}

Esses testes foram realizados em canteiro, objetivando-se comparar a eficiência da separação em escala-piloto com aquela obtida em escala de laboratório. Os testes seguiram a mesma metodologia dos testes em escala de laboratório. Foi delimitada, dentro do canteiro, uma região de 1,0 $\mathrm{m}$ de largura por $0,90 \mathrm{~m}$ de comprimento utilizando-se uma estrutura de madeira e tela de polietileno. Dentro dessa região foi colocada uma camada de 0,30 $\mathrm{m}$ de húmus. Os eletrodos de tela foram postos ao longo da largura do canteiro e apresentavam, em ambas as laterais, uma região de $0,25 \mathrm{~m}$ de comprimento. A Figura 3 mostra a estrutura montada para a realização dos testes em canteiro.

Ao serem acomodadas, as minhocas foram distribuídas uniformemente ao longo da região dos testes, a uma densidade de 2.000 minhocas por $\mathrm{m}^{2}$ em seções delimitadas por chapas galvanizadas previamente inseridas na região. As chapas foram mantidas até o momento de aplicação do pulso para garantir a distribuição uniforme ao longo da região de testes; somente os pulsos elétricos que proporcionaram melhor eficiência de separação, em laboratório, foram testados (Figura 4).

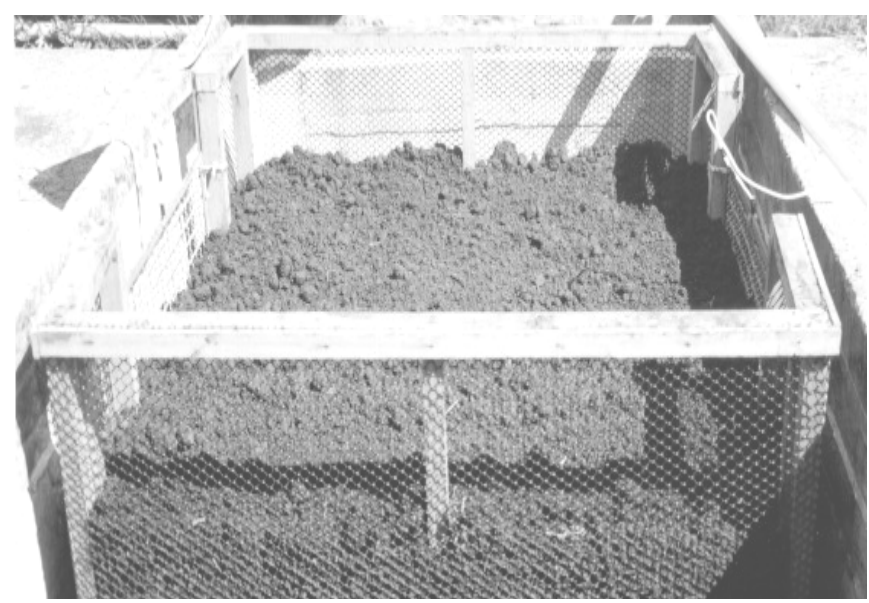

Figura 3. Estrutura para a realização dos testes em canteiro

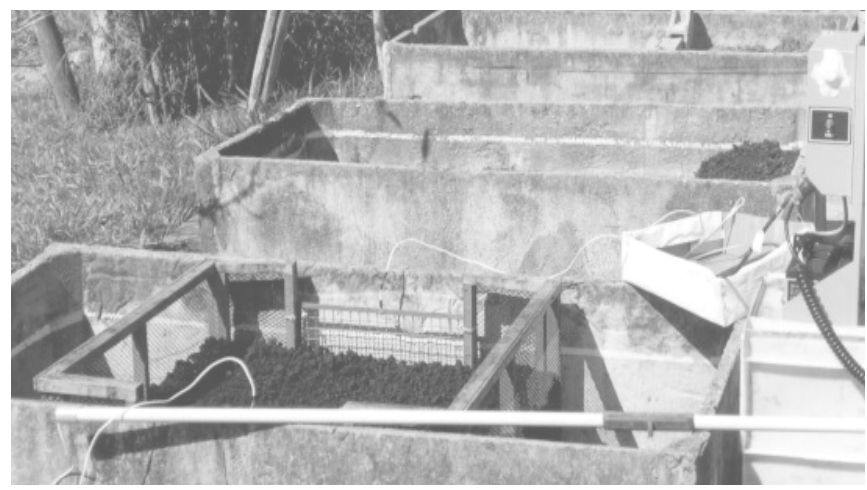

Figura 4. Visão geral do experimento realizado em canteiro

Mediu-se a tensão ao longo do substrato na região entre os eletrodos e nas bordas, a cada $0,06 \mathrm{~m}$, a partir do cátodo em três diferentes profundidades $(0,04 ; 0,15$ e 0,28 m). Obteve-se, assim, o perfil do gradiente de tensão em função da profundidade e, conseqüentemente, em função do teor de umidade. Mediu-se, daí, a tensão, V, entre os eletrodos e a corrente no circuito, I, possibilitando determinar a resistência elétrica do substrato.

\section{Análise estatística}

Fez-se uma combinação de quatro tempos de exposição (1, 2,3 , e 4 h) e duas freqüências (1 e $5 \mathrm{~Hz}$ ) para as espécies estudadas. Os tratamentos foram dispostos em delineamento inteiramente ao acaso, com três repetições, avaliando-se os efeitos dos tratamentos em relação aos índices de deslocamento $\left(\mathrm{I}_{\mathrm{D}}\right)$ e de separação $\left(\mathrm{I}_{\mathrm{S}}\right)$. Os dados foram interpretados por meio de análise de variância e regressão. Escolheram-se os modelos com base na significância dos coeficientes de regressão pelo teste " $F$ ", adotando-se o nível de $1 \%$ de probabilidade, e no coeficiente de determinação.

\section{Análise econômica}

Para a análise da viabilidade econômica de utilização de pulsos elétricos controlados em comparação com os processos tradicionais de separação, fez-se um levantamento dos valores do custo da mão-de-obra, da tarifa de energia elétrica (monômia rural), da produtividade para a separação por meio de catação e de iscas, do tempo de disponibilidade da mão-de-obra (diahomem) para uma instalação típica de minhocultura (Lapponi, 
1997; Camargo, 1998; Frizzone \& Silveira, 2000). Nesta análise, procurou-se determinar o valor de comercialização do equipamento que viabilizaria a sua utilização. Foram analisados os seguintes métodos de comparação de opções de investimento: Relação benefício/custo (RBC), Tempo de retorno do capital (TRC), Análise do valor presente líquido (VPL) e Taxa interna de retorno (TIR).

\section{RESULTADOS E DISCUSSÃO}

A Tabela 1 apresenta os resultados dos testes efetuados para a caracterização elétrica do substrato. Com esses dados é possível realizar o projeto de gerador de pulsos adequado para a minhocultura, pois se tem a estimativa de potência e de energia necessárias ao processo.

Tabela 1. Características elétricas do substrato

\begin{tabular}{|c|c|c|c|}
\hline \multirow[b]{2}{*}{ Característica } & \multirow[b]{2}{*}{ Unidade } & \multicolumn{2}{|c|}{ Testes } \\
\hline & & $\begin{array}{l}\text { Corrente } \\
\text { Contínua }\end{array}$ & $\begin{array}{c}\text { Pulsos } \\
\text { Controlados }\end{array}$ \\
\hline Resistividade elétrica & $\Omega_{\mathrm{m}}$ & 5,85 & - \\
\hline Energia por pulso & $\mathrm{J}$ & - & 8,92 \\
\hline $\begin{array}{l}\text { Demanda pico a pico } \\
\text { por eletrodo }\end{array}$ & W & - & $1.288,37$ \\
\hline Demanda média por eletrodo & W & - & 8,92 \\
\hline $\begin{array}{l}\text { Demanda pico a pico por } \\
\text { metro linear de eletrodo }\end{array}$ & W & - & $2.576,70$ \\
\hline $\begin{array}{l}\text { Demanda média por metro } \\
\text { linear de eletrodo }\end{array}$ & W & - & 17,84 \\
\hline
\end{tabular}

A demanda pico a pico, determinada a partir da energia por pulso e em função da freqüência, indica o valor máximo de potência que deve ser demandada pelo gerador no período equivalente ao patamar do pulso gerado. $\mathrm{O}$ valor de demanda média está condizente com o decaimento exponencial da tensão, pois a tensão máxima é mantida durante $4 \mathrm{~ms}$, enquanto no tempo restante, $996 \mathrm{~ms}$, ocorre o decaimento. No intervalo de tempo igual a $23 \mathrm{~ms}$ o decaimento, aproximadamente exponencial, já ocorreu e, durante os restantes 973 ms, o sinal é nulo, implicando numa demanda média baixa.

\section{Testes em laboratório}

A Tabela 2 apresenta a análise de variância do índice de deslocamento $\left(\mathrm{I}_{\mathrm{D}}\right)$ e do índice de separação $\left(\mathrm{I}_{\mathrm{S}}\right)$ em função dos fatores freqüência e tempo de exposição ao pulso, para a espécie Eudrilus Eugeniae. Observa-se efeito significativo (p $<0,01)$ de freqüência, tempo de exposição e interação tempo de exposição $\mathrm{x}$ freqüência para todas as variáveis. Com base nesses resultados, procedeu-se ao desdobramento da interação.

A Tabela 3 mostra as equações ajustadas para cada frequiência estudada. $\mathrm{O}$ modelo quadrático foi o que melhor descreveu o comportamento dos índices de deslocamento e de separação, em função do tempo de exposição aos pulsos para cada freqüência.

A Figura 5 indica as curvas de ajuste para o índice de deslocamento em função do tempo, para as freqüências
Tabela 2. Análise de variância dos índices de deslocamento $\left(\mathrm{I}_{\mathrm{D}}\right)$ e de separação $\left(\mathrm{I}_{\mathrm{S}}\right)$ para minhoca Eudrilus eugeniae

\begin{tabular}{lccl}
\hline & & \multicolumn{2}{c}{ Quadrado Médio } \\
\cline { 3 - 4 } \multicolumn{1}{c}{ FV } & GL & $\mathrm{I}_{\mathrm{D}}$ & \multicolumn{1}{c}{$\mathrm{I}_{\mathrm{S}}$} \\
\hline Freqüência & 1 & $1.561,7060^{* *}$ & $3.444,0110^{* *}$ \\
Resíduo (a) & 4 & 1,2520 & 3,4716 \\
Tempo de exposição & 3 & $286,0227^{* *}$ & $605,6238^{* *}$ \\
Tempo de exposição x & 3 & $66,9922^{* *}$ & $155,7049^{* *}$ \\
Freqüência & & & 19,7520 \\
Resíduo (b) & 12 & 1,80 & 4,86 \\
CV(\%) parcela & & 5,27 & 11,54 \\
CV(\%) subparcela & & \multicolumn{2}{c}{} \\
\hline
\end{tabular}

Tabela 3. Equações de regressão ajustadas para os índices de deslocamento $\left(I_{D}\right)$ e de separação $\left(I_{S}\right)$, em função do tempo (T), para a espécie Eudrilus eugeniae, para as respectivas freqüências (Hz) e os respectivos coeficientes de regressão

\begin{tabular}{cccc}
\hline $\mathrm{Hz}$ & Variáveis & Equação de Ajuste & $\mathrm{R}^{2}$ \\
\hline 1 & $\mathrm{I}_{\mathrm{D}}$ & $=39,3917+20,2450^{* *} \mathrm{~T}-2,6417^{*} \mathrm{~T}^{2}$ & 0,96 \\
5 & $\mathrm{I}_{\mathrm{D}}$ & $=34,4250+16,8283^{\text {ns }} \mathrm{T}-2,9917^{* *} \mathrm{~T}^{2}$ & 0,82 \\
1 & $\mathrm{I}_{\mathrm{S}}$ & $=3,9669+30,3767^{* *} \mathrm{~T}-3,9500^{* *} \mathrm{~T}^{2}$ & 0,97 \\
5 & $\mathrm{I}_{\mathrm{S}}$ & $=0,3417+21,8683^{*} \mathrm{~T}-3,8250^{*} \mathrm{~T}^{2}$ & 0,86 \\
\hline *F significativo a nível de5\%; ** F significativo a nível de 1\%; ${ }^{\text {ns não significativo }}$
\end{tabular}

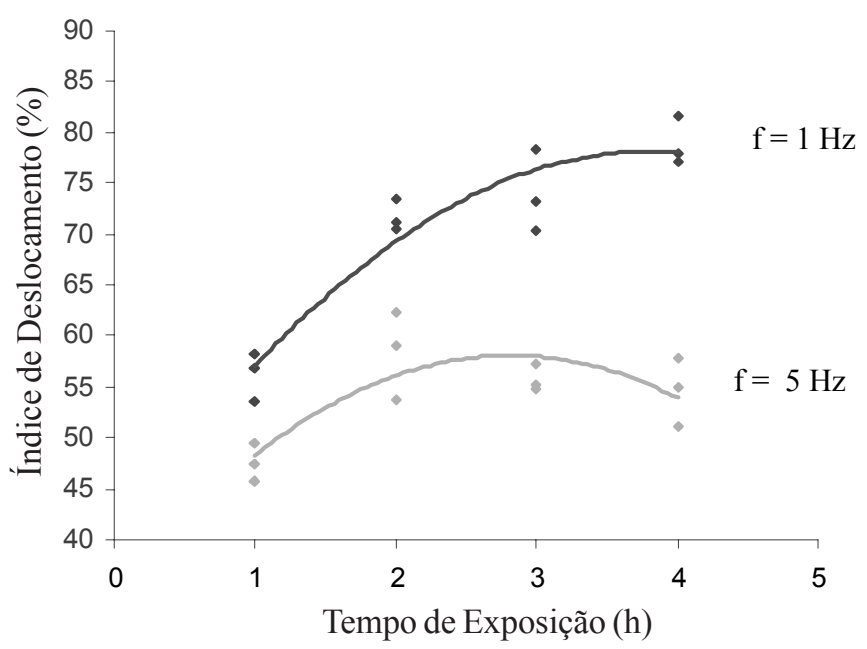

Figura 5. Estimativa do índice de deslocamento em função do tempo de exposição aos pulsos para minhocas Eudrilus eugeniae para as respectivas freqüências (f)

estudadas. Observa-se que houve resposta mais expressiva aos pulsos, na freqüência de $1 \mathrm{~Hz}$, e o índice de deslocamento máximo, segundo o modelo, foi de 78,18\% obtido para o tempo de exposição de $3,83 \mathrm{~h}$.

A resposta apresentada na freqüência de $5 \mathrm{~Hz}$ pode ser justificada em função do estresse que a seqüência de pulsos pode ter causado aos animais, tendo em vista que, para uma freqüência maior, quando o animal está recebendo um novo pulso ele se encontra ainda sob o efeito do pulso anterior, não permitindo, desta forma, o relaxamento de sua musculatura. Para esta freqüência, o índice de deslocamento máximo obtido, segundo o modelo, foi de $58,09 \%$ em um tempo de exposição de $2,81 \mathrm{~h}$. 
Para o índice de separação verifica-se comportamento semelhante ao descrito para o índice de deslocamento. $\mathrm{Na}$ Figura 6 tem-se as curvas de ajuste para o índice de separação, em função do tempo para as freqüências estudadas, e a resposta para a freqüência de $1 \mathrm{~Hz}$ é, também, mais expressiva em relação à freqüência de $5 \mathrm{~Hz}$, e o tempo no qual, segundo o modelo, se obtém o máximo índice de separação, $62,37 \%$, está em torno de $3,85 \mathrm{~h}$. Para a freqüência de $5 \mathrm{~Hz}$ o índice de separação máximo está em torno de $31,60 \%$ em um tempo de exposição de $2,86 \mathrm{~h}$.

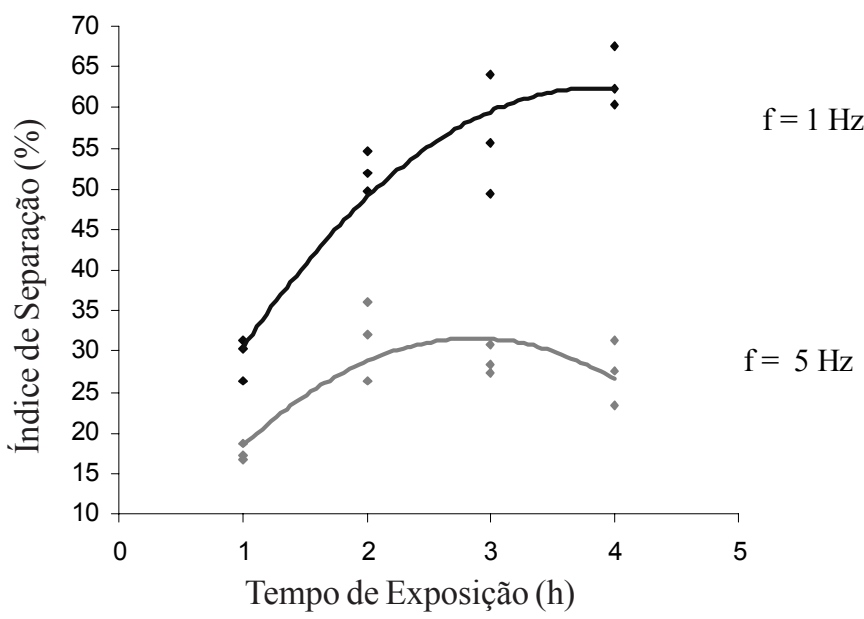

Figura 6. Estimativa do índice de separação em função do tempo de exposição aos pulsos para minhocas Eudrilus eugeniae para as respectivas freqüências (f)

A Tabela 4 apresenta as médias dos índices de deslocamento e de separação em cada tempo de exposição nas freqüências estudadas, para a espécie Eudrilus eugeniae. Constata-se, nesse quadro, que o maior valor, tanto do índice de deslocamento quanto do índice de separação, ocorreu na freqüência de $1 \mathrm{~Hz}$ e em todos os tempos. A Tabela 4 mostra também a significância dos dados quando submetidos ao teste de Tukey.

Tabela 4. Média* dos índices de deslocamento e de separação em cada tempo de exposição nas freqüências $(\mathrm{Hz})$ estudadas para minhocas Eudrilus eugeniae

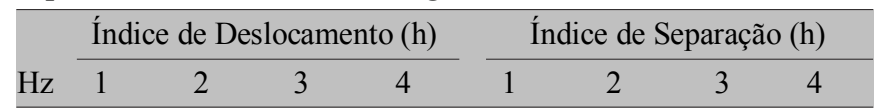

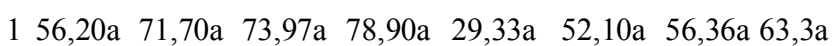

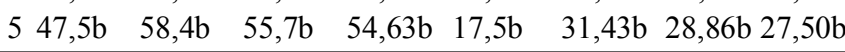

* As médias seguidas de mesma letra nas colunas, para cada tempo, não diferem entre si, a $5 \%$ de probabilidade pelo teste de Tukey

Os resultados de Moraes (1999) testes de minhocas das espécies Eudrilus engeniae submetidas a pulsos semelhantes aos utilizados, mas com espessura de canteiro de cerca de $3 \mathrm{~cm}$ de húmus (cerca de um décimo do utilizado), devem servir de referência. Os melhores índices de índices deslocamento encontrados por Moraes foram da ordem de 83,7\%. Ressaltase que os tempos de exposição aos pulsos e o deslocamento máximo requerido pelos vermes, também foram diferentes.

\section{Controle de sobrevivência}

Analisou-se o percentual de sobrevivência das minhocas da espécie Eudrilus eugeniae após 7, 14 e 21 dias da exposição aos pulsos, em função das combinações de tensão, freqüência e tempo de exposição.

O percentual de sobrevivência foi de $100 \%$ para os pulsos com freqüência de $1 \mathrm{~Hz}$, ou seja, todas as 70 minhocas utilizadas por repetição sobreviveram após os 21 dias de observação; para os pulsos com freqüência de $5 \mathrm{~Hz}$, o percentual de sobrevivência ficou em torno de $96,5 \%$. O percentual de morte se deve à maior taxa de pulsos, pois quando o animal recebe um pulso ele ainda se encontra sob efeito do pulso anterior, não tendo tempo para que sua musculatura assimile a seqüência de pulsos, levando o animal a fortes contorções provocando, inclusive, em alguns casos, perda de pedaços, principalmente da cauda. Portanto, não se recomenda o uso de freqüências superiores a $1 \mathrm{~Hz}$ para separação de minhocas do húmus.

\section{Análise econômica}

Propuseram-se valores de comercialização do equipamento e se realizou o estudo da taxa interna de retorno (TIR), valor presente líquido (VPL), relação benefício/custo (RBC) e tempo de retorno do capital (TRC), para avaliar a possibilidade de investimento ou não. A Tabela 5 apresenta os dados relativos à produtividade, consumo de energia elétrica, tempo de utilização do equipamento gerador de pulsos, quantidade de matéria-prima e tempo de disponibilidade da mão-de-obra (diahomem) para uma instalação típica de minhocultura. Nesta análise procurou-se estimar o valor do equipamento para verificar a viabilidade econômica de utilização de pulsos

Tabela 5. Dados relativos ao tamanho das instalações, ciclos de trabalho, consumo de energia elétrica, matéria-prima, produtividade e tempo de disponibilidade da mão-de-obra para uma instalação típica de minhocultura

\begin{tabular}{|c|c|c|}
\hline \multirow[b]{2}{*}{ Item e Unidade } & \multicolumn{2}{|c|}{ Método utilizado* } \\
\hline & $\begin{array}{c}\text { CM } \\
\text { e ACI }\end{array}$ & $\begin{array}{l}\text { Pulsos } \\
\text { elétricos }\end{array}$ \\
\hline Tamanho da minhocultura - $\mathrm{m}^{2}$ & 200 & 200 \\
\hline Comprimento de canteiro - $\mathrm{m}$ & 10 & 10 \\
\hline Ciclo de trabalho - separação/mês & 1 & 0,86 \\
\hline Funcionamento do equipamento - $\mathrm{h} /$ mês & - & 207,03 \\
\hline Pot. média solicitada pelo equipamento - $\mathrm{kW}$ & - & 0,12 \\
\hline Consumo de energia elétrica - $\mathrm{kWh} /$ ano & - & 295,47 \\
\hline Quantidade de esterco consumida - kg/mês & 45429 & 54514 \\
\hline Produtividade $-\mathrm{m}^{2} / \mathrm{h}$ & 1,43 & 3,86 \\
\hline \multirow{2}{*}{$\begin{array}{c}\text { Produção mensal de vermes }- \text { minh. } / \mathrm{m}^{2} / \text { ciclo } \\
- \text { minh. } / \text { ciclo }\end{array}$} & 2100 & 2100 \\
\hline & 420000 & 420000 \\
\hline \multirow{2}{*}{$\begin{aligned} \text { Produção mensal húmus }-\mathrm{kg} / \mathrm{m}^{2} / \text { ciclo } \\
-\mathrm{kg} / \text { ciclo }\end{aligned}$} & 159 & 159 \\
\hline & 31800 & 38160 \\
\hline Horas de atividade - $\mathrm{h} /$ mês & 140 & 62 \\
\hline Turno de trabalho - horas/dia & 8 & 8 \\
\hline
\end{tabular}

*CM - Catação manual; ACI - atração com iscas 
elétricos em comparação com o processo tradicional de catação e iscas.

$\mathrm{Na}$ Tabela 6 apresentam-se os dados referentes ao levantamento dos valores relativos à tarifa de energia elétrica (monômia rural), aos custos da energia elétrica, da matéria-

Tabela 6. Valores relativos a custos de energia, de mão-deobra, de matéria-prima, preços de comercialização de produtos e índices para análise econômica

\begin{tabular}{|c|c|c|}
\hline \multirow[b]{2}{*}{ Item e Unidade } & \multicolumn{2}{|c|}{ Método utilizado* } \\
\hline & $\begin{array}{l}\mathrm{CM} \mathrm{e} \\
\text { com iscas }\end{array}$ & $\begin{array}{l}\text { Pulsos } \\
\text { elétricos }\end{array}$ \\
\hline Tarifa da energia elétrica - $\mathrm{R} \$ \mathrm{kWh}^{-1}$ & - & 0,15 \\
\hline Custo da energia elétrica - $\mathrm{R} \$ \mathrm{ano}^{-1}$ & - & 44,27 \\
\hline Custo do esterco - $\mathrm{R} \$ / \mathrm{kg}$ & 0,10 & 0,10 \\
\hline \multirow{2}{*}{$\begin{aligned} \text { Mão-de-obra (sem encargos sociais) - } \mathrm{R} \$ \text { hora }^{-1} \\
-\mathrm{R} \$ \mathrm{mês}^{-1}\end{aligned}$} & 1,65 & 1,65 \\
\hline & 231,64 & 102,85 \\
\hline Preço do húmus - $\mathrm{R} \$ \mathrm{~kg}^{-1}$ & 0,15 & 0,15 \\
\hline Preço das minhocas - $\mathrm{R} \$ \mathrm{~kg}^{-1}$ & 5 & 5 \\
\hline Juros (custo de oportunidade) - $\%$ ano $^{-1}$ & 15 & 15 \\
\hline $\begin{array}{l}\text { Aumento da energia elétrica acima } \\
\text { da inflação - \% ano }\end{array}$ & - & 2 \\
\hline Horizonte de planejamento - Ano & 15 & 15 \\
\hline
\end{tabular}

prima, da mão-de-obra, preço de venda dos produtos (húmus e minhocas) e índices econômicos.

A Tabela 7 mostra a receita bruta da venda da produção gerada pelos dois processos analisados, em cuja análise foi suposto que o uso do gerador de pulsos proporcionaria diminuição na necessidade de mão-de-obra, de cerca de 55\%.

Tabela 7. Receita mensal bruta em função da venda de húmus e minhocas

\begin{tabular}{lcccccc}
\hline \multirow{2}{*}{ Produto } & \multicolumn{4}{c}{ Método de separação } \\
\cline { 2 - 3 } & $\begin{array}{c}\text { Catação manual e } \\
\text { atração com iscas }\end{array}$ & & \multicolumn{2}{c}{ Pulsos elétricos } \\
\cline { 2 - 3 } \cline { 5 - 6 } & $\begin{array}{c}\text { Produção } \\
\text { mensal (kg) }\end{array}$ & $\begin{array}{c}\text { Receita } \\
\text { mensal (R\$) }\end{array}$ & $\begin{array}{c}\text { Produção } \\
\text { mensal (kg) }\end{array}$ & $\begin{array}{c}\text { Receita } \\
\text { mensal (R\$) }\end{array}$ \\
\hline Minhocas & 600 & $3.000,00$ & & 720 & $3.600,00$ \\
Húmus & 31.800 & $4.770,00$ & & 38.160 & $5.724,00$ \\
\hline Receita bruta total & $7.770,00$ & & $9.324,00$ \\
\hline
\end{tabular}

Na Tabela 8 mostram-se os valores obtidos na análise e, nela, verifica-se que, a medida em que se aumenta o valor proposto para o equipamento, diminui-se a relação benefício/ custo mas se aumenta o tempo de retorno do capital investido. Os valores presentes líquidos da utilização de pulsos elétricos (VPLpulsos) e da catação (VPLcatação) representam as receitas atuais em ambos os processos. Observa-se, então, que a utilização de pulsos elétricos na minhocultura gera um ganho médio, ao longo do horizonte de planejamento, de $\mathrm{R} \$ 55.313,54$, ou seja, uma economia de cerca de $27 \%$.

Analisando-se os dados da Tabela 8, percebe-se a variação da taxa interna de retorno do investimento em função do valor proposto para o equipamento e se verifica que, à medida que
Tabela 8. Valores presentes líquidos (VPL), taxa interna de retorno (TIR), relação benefício/custo (RBC) e tempo de retorno de capital (TRC) em função do preço do equipamento

\begin{tabular}{cccccc}
$\begin{array}{c}\text { PG* } \\
(\mathrm{R} \$)\end{array}$ & $\begin{array}{c}\text { VPLpulsos } \\
(\mathrm{R} \$)\end{array}$ & $\begin{array}{c}\text { VPLcatação } \\
(\mathrm{R} \$)\end{array}$ & $\begin{array}{c}\text { TIR } \\
(\%)\end{array}$ & RBC & $\begin{array}{c}\text { TRC } \\
(\mathrm{mês})\end{array}$ \\
\hline $1.000,00$ & $261.409,77$ & $204.096,23$ & 999,3 & 58,31 & 1,20 \\
$2.000,00$ & $260.409,77$ & $204.096,23$ & 499,6 & 29,16 & 2,28 \\
$3.000,00$ & $259.409,77$ & $204.096,23$ & 333,0 & 19,44 & 3,12 \\
$4.000,00$ & $258.409,77$ & $204.096,23$ & 249,7 & 14,58 & 3,72 \\
$5.000,00$ & $257.409,77$ & $204.096,23$ & 199,8 & 11,60 & 4,44 \\
Média & $259.490,77$ & $204.096,23$ & - & - & - \\
* PG - Preço gerador & & & &
\end{tabular}

se aumenta o valor do equipamento, ou seja, o valor a ser investido, ocorre a diminuição da taxa de retorno, mas para todos os preços propostos para o equipamento, a TIR acenou para possibilidade e viabilidade do investimento, pois os valores apresentados estão todos acima do valor do custo de oportunidade de $15 \%$ ao ano, para o qual foram feitas as análises. Para todos os preços considerados de geradores de pulsos elétricos, a taxa interna de retorno foi superior à taxa de juros, mostrando que o investimento na aquisição desses equipamentos é um excelente negócio, visto que remuneração do capital investido que este equipamento trará, seria de aproximadamente 11 a 58 vezes maior durante o horizonte de planejamento, se este mesmo capital fosse aplicado em um investimento que remunerasse o capital investido em $15 \%$ ao ano.

\section{CONCLUSÕES}

1. Em geral, as minhocas submetidas aos pulsos elétricos controlados se deslocaram preferencialmente no sentido do eletrodo positivo (cátodo).

2. Os fatores freqüência e tempo de exposição ao pulso apresentaram efeitos significativos sobre o índice de deslocamento e no índice de separação.

3. O maior valor, tanto do índice de deslocamento quanto do índice de separação, para a espécie Eudrilus eugeniae, ocorreu na freqüência de $1 \mathrm{~Hz}$ e em todos os tempos.

4. O maior valor de índice de deslocamento para a espécie Eudrilus eugeniae foi de 78,9\% para a tensão de $200 \mathrm{~V}$, freqüência de $1 \mathrm{~Hz}$ e tempo de exposição de 3,83 h; já o maior valor de índice de separação para esta espécie foi de $62,37 \%$ para tensão de $200 \mathrm{~V}$, freqüência de $1 \mathrm{~Hz}$ e tempo de exposição de $3,854 \mathrm{~h}$.

5. É possível realizar projeto de gerador de pulsos adequado para a minhocultura para espécie Eudrilus eugeniae, pois se tem a caracterização dos pulsos elétricos, além da estimativa de potência e energia necessárias ao processo.

6. Para a situação estudada, a utilização de pulsos elétricos controlados para a separação de minhocas do húmus, gera um ganho médio ao longo da vida útil estimada, de $\mathrm{R} \$ 55.314,54$, ou seja, cerca de $27 \%$ de economia.

7. Para todos os preços propostos para o equipamento, a TIR acenou para a viabilidade do investimento, pois os valores 
apresentados estão todos acima do valor proposto como custo de oportunidade, ou seja, $15 \%$ ao ano.

\section{LITERATURA CITADA}

Almeida, P.C.C. Minhocultura, Cuiabá: Edição SEBRAE, 1999. $114 \mathrm{p}$.

Àvila, U. Criação de minhocas sem segredo, Guaíba: Editora Agropecuária, 1999. 72p.

Bradway, W.E.; Moore, A.R. The locus of the action of the galvanic current in the earthworm, Lumbricus terrestris. Journal of Cellular Comparative Physiology, New York, v.15, 1940.p. 47-54.

Calvert, C.C. Use of animal excreta for microbial and insect protein synthesis, Journal of Animal Science, Philadelphia,v.48. n.1, 1979. p.178-191.

Camargo, I.M. de T. Noções básicas de engenharia econômica: aplicações ao setor elétrico. Brasília: FINATEC, 1998. 160p.

Frizzone, J.A.; Silveira, S.F.R. Avaliação e custos de projetos de irrigação. In: Curso Seminário Energia na Agricultura, 1, 2000. Uberaba. Anais... Uberaba: CEMIG, 2000. p.1-87.

Kurtz, I.; Schrank, A.R. Bioelectrical properties of intact and regenerating earthworms, Eisenia fotida. Physiological zoology, Chicago, v.28, p.322-330, 1955.

Lapponi, J.C. Avaliação de projetos de investimento: modelos em excel. São Paulo: Lapponi Treinamento e Editora Ltda, 1996.263p.
Martinez, A.A. A grande e poderosa minhoca - manual prático do minhocultor. Guaíba: FUNEP, Editora Agropecuária, 1995. $137 \mathrm{p}$.

Moraes, M.J. de. Utilização de sinais elétricos para a separação de minhocas (Eudrilus eugeniae e Eisenia foetida) do húmus. Viçosa: UFV. 1999. 88p. Dissertação Mestrado

Motter, O.F.; Kiehl, E.J.; Kawai, H.; Medel, L.E.; Yoshimoto, H. Utilização de minhocas na produção de composto orgânico. São Paulo: CETESB, 1990. 8p.

Reinecke, A.J.; Kriel, J.R. Influence of temperature on the reproduction of the earthworm Eisenia foetida (oligachaeta), Journal of Zoology, London, v.16, n.2, p. 96100, 1981.

Righi, G. Minhocas de Mato Grosso e de Rondônia, Brasília: FAPEMIG AED, 1989.158p.

Rossi, F.; Shimoda, E. Criação de minhocas - manual, Viçosa: Centro de Produções Técnicas, 1996. 29p.

Rushton, S.P.; Luff,M.L. A new electrical method for sampling earthworm populations, Pedobiologia, New York, v.26, 1984, p.15-19.

Satchell, J.E. An electrical method of sampling earthworm populations, In: Kevan, D.K. Mc. E. Soil Zoololy. London: Butteworths Scientific, 1955. p.356-364.

SENAR - RS. Criação de minhocas e produção de húmus Manual, Porto Alegre: SENAR, 1994. 25p.

Thielemann, U. The octet-method for sampling earthworm populations, Pedobiologia, New York, v.29, 1986, p.297-303.

Vieira, M.L. Produção de minhocas em dejeto suínos estabilizados e valor nutritivo da farinha de minhocas para suínos. Viçosa: UFV. 1997. 59p. Dissertação Mestrado 